Article

\title{
Earthquake-Induced Landslide Mapping for the 2018 Hokkaido Eastern Iburi Earthquake Using PALSAR-2 Data
}

\author{
Yusupujiang Aimaiti ${ }^{1} * \mathbb{\infty}$, Wen Liu ${ }^{1} \mathbb{D}$, Fumio Yamazaki ${ }^{2}$ and Yoshihisa Maruyama ${ }^{1}$ \\ 1 Graduate School of Engineering, Chiba University, Chiba 263-8522, Japan; wen.liu@chiba-u.jp (W.L.); \\ ymaruyam@tu.chiba-u.ac.jp (Y.M.) \\ 2 National Research Institute for Earth Science and Disaster Resilience, Tsukuba, Ibaraki 305-0006, Japan; \\ fumio.yamazaki@bosai.go.jp \\ * Correspondence: agda1132@chiba-u.jp; Tel.: +81-43-290-3528
}

Received: 30 August 2019; Accepted: 8 October 2019; Published: 10 October 2019

\begin{abstract}
Timely information about landslides during or immediately after an event is an invaluable source for emergency response and management. Using an active sensor, synthetic aperture radar (SAR) can capture images of the earth's surface regardless of weather conditions and may provide a solution to the problem of mapping landslides when clouds obstruct optical imaging. The 2018 Hokkaido Eastern Iburi earthquake $\left(M_{w} 6.6\right)$ and its aftershocks not only caused major damage with severe loss of life and property but also induced many landslides across the area. To gain a better understanding of the landslides induced by this earthquake, we proposed a method of landslide mapping using pre- and post-event Advanced Land Observation Satellite 2 Phased Array L-band Synthetic Aperture Radar 2 (ALOS-2 PALSAR-2) images acquired from both descending and ascending orbits. Moreover, the accuracy of the classification results was verified by comparisons with high-resolution optical images, and ground truth data (provided by GSI, Japan). The detected landslides show a good match with the reference optical images by visual comparison. The quantitative comparison results showed that a combination of the descending and ascending intensity-based landslide classification had the best accuracy with an overall accuracy and kappa coefficient of $80.1 \%$ and 0.45 , respectively.
\end{abstract}

Keywords: the Hokkaido Eastern Iburi earthquake; landslides; SAR intensity; coherence; optical satellite images; quantitative comparison of SAR images

\section{Introduction}

Earthquakes are one of the most dangerous natural disasters in the world. In general, a moderate to severe earthquake can trigger landslides in mountainous regions [1]. These landslides may cause injuries and loss of human life, may cause damage to infrastructure, and may lead to enormous economic losses. Therefore, quickly identifying and mapping these landslides has great importance for emergency response and restoration activities after disasters [2].

Currently, owing to their capability for wide-area observations, relatively low cost and rapid advances, remote sensing satellite observations have enabled us to effectively detect and monitor landslides at individual and regional scales. Optical (e.g., Landsat, QuickBird, GeoEye-1, and WorldView-2) and synthetic aperture radar (SAR) data (e.g., TerraSAR -X, and COSMO-SkyMed) are the most commonly used satellite sensors for detecting and analyzing slowly to rapidly moving landslides [3-5]. When cloud-free optical imagery is unavailable and the coverage of ground-based observations is limited, SAR data can be an optimal solution owing to the capability of day-and-night and all-weather imaging [6,7]. Currently, the number of SAR sensors has vastly increased. The datasets from previous SAR sensors (e.g., ERS-1/-2, ENVISAT and ALOS PALSAR) and the new generation of C, 
X, and L-band SAR images provided by RADARSAT-2, Sentinel-1A, ALOS-2 PALSAR-2, TerraSAR-X, Tandem- $X$ and the COSMO-SkyMed constellation have enabled us to determine historical and current landslides with high precision [8-10].

SAR products are routinely used for the detection of surface changes or damages caused by earthquakes. The SAR intensity, interferometric coherence, SAR polarimetry have been largely studied by scientists for earthquake damage estimation purpose. Recently Watanabe et al. [11] detected the building damages in the 2015 Gorkha, Nepal, earthquake using interferometric SAR coherence-change technique with coherence filter and polarization; Karimzadeh and Matsuoka [12] assessed the building damages caused by the 2016 Amatrice earthquake with multitemporal SAR coherence and intensity methods using dual-polarized SAR data, and developed linear discriminant functions to generate the damage proxy maps; Moya et al. [13] identified the collapsed buildings due to the 2011 Tohoku earthquake/tsunami and the 2016 Kumamoto earthquake using three-dimensional Gray Level Co-occurrence Matrix (3DGLCM); Ferrentino et al. [14] proposed a method to detect damages in dual polarimetric (DP) coherent SAR imagery based on the optimization of the complete covariance matrices collected before and after earthquakes.

SAR data are also widely used in extracting landslides and geological hazards. Burrows et al. [7] proposed a boxcar and sibling-based coherence (Bx-S) method using Sentinel 1A coherence data for detecting landslides triggered by the 2015 Gorkha earthquake. Goorabi [15] detected the Maleh-Kabood landslide caused by the Azgleh, Iran, earthquake comparing the pre- and post-earthquake coherence histograms using Sentinel-1A/B data. Mondini et al. [16] detected 32-case landslides worldwide (e.g., rainfall, earthquake and rapid snow melting-induced landslides), using photo-interpretive methods as measures of changes in amplitude in pre- and post-event Sentinel-1 images. Uemoto et al. [17] proposed a landslide detection method utilizing height differences derived from pre- and post-event airborne Pi-SAR2 digital elevation models (DEMs) combined with amplitude differences and applied this method to landslides triggered by the 2016 Kumamoto earthquake. For other types of landslides (e.g., slow-moving landslides), differential SAR interferometry (DInSAR) and advanced-DInSAR time-series have become common methods for evaluating landslide activity and for detecting precursor $[10,18-20]$.

On 6 September 2018, a powerful earthquake of moment magnitude $M_{W} 6.6$ occurred off Iburi Subprefecture in southern Hokkaido, Japan. The earthquake struck just one day after typhoon Jebi (No. 21 in Japan) had produced torrential rains in the region [21]. After the earthquake, up to 6000 landslides occurred near the center of Atsuma town due to the heavy rain-soaked subsurface deposits of volcanic soil in the region, turning them into a geologically "greasy" layer [21,22]. As an emergency response coordination effort, the Geospatial Information Authority of Japan (GSI) took aerial photographs [23] on the day and several days after the earthquake (6, 8 and 11 September 2018), and they mapped the landslide area using those aerial photographs and published their results on their website [23]. Fujiwara et al. [24] identified and analyzed surface displacements associated with this earthquake. Shao et al. [25] produced a landslide susceptibility map of the area by applying logistic regression (LR) and support vector machine (SVM) to the high-resolution Planet (optical) images. Mondini et al. [16] applied photo-interpretive methods to detect the Hokkaido earthquake-induced landslides as measures of changes in amplitude in pre- and post-event Sentinel-1 images. However, a detailed quantitative analysis of the landslides has not yet been reported.

In this study, we present a rule-based method to identify and map the earthquake-induced landslides in Hokkaido, taking advantage of ALOS-2 PALSAR-2 images obtained before and after the event. Moreover, high-resolution optical images from WorldView-2 and GeoEye-1 and ground truth data [23] were used as references and for validation purposes.

\section{Study Area}

An earthquake with a moment magnitude of $\mathrm{M}_{\mathrm{w}} 6.6$ at a depth of $37 \mathrm{~km}$ struck the Iburi Subprefecture in southern Hokkaido, Japan on September 6, 2108 at 03:08 AM, Japan time 
(UTC: 5 September, 06:08 PM). The epicenter of the 2018 Hokkaido Eastern Iburi earthquake was near Tomakomai and located at $42.72^{\circ}$ North, and $142.0^{\circ}$ East, and the Japan Meteorological Agency (JMA) registered a maximum intensity of 7 on the JMA Seismic Intensity scale at Atsuma town. The aftershock focal mechanisms are characterized by an ENE-SWS compression around the northern, southern, and Shallow Iburi (SI) faults [26]. The area is composed of Neogene sedimentary rocks as its basement and covered mostly up with air-fall lapilli-sized pumice layers from Tarumai volcano to the east. Surface soil layers covering low to middle mountain ranges are inter-bedded with the pumice and ash. The total thickness of the surface layer is about 4-5 m. Most landslides are shallow, several meters deep-seated, and are mostly classified as planar types and spoon types [21]. Landslides were densely distributed over hilly regions with an elevation of 200-400 $\mathrm{m}$ [27].

Considering the availability of ALOS-2 PALSAR-2 images and the reference optical data, we chose an area near the Atsuma town that spanned from $42.43^{\circ}$ to $42.48^{\circ}$ North latitude and from $141.52 .5^{\circ}$ to $141.60^{\circ}$ East longitude as the study area (Figure $1 \mathrm{a}$ ). Figure $1 \mathrm{~b}$ shows the landslide distribution map produced by the GSI, Japan [23], and we used this map as ground truth data. From Figure 1c, we can see that the elevation of the study area ranges from $48 \mathrm{~m}$ to $348 \mathrm{~m}$ and that most landslides occurred between high to moderate elevations of up to $348 \mathrm{~m}$ [28].
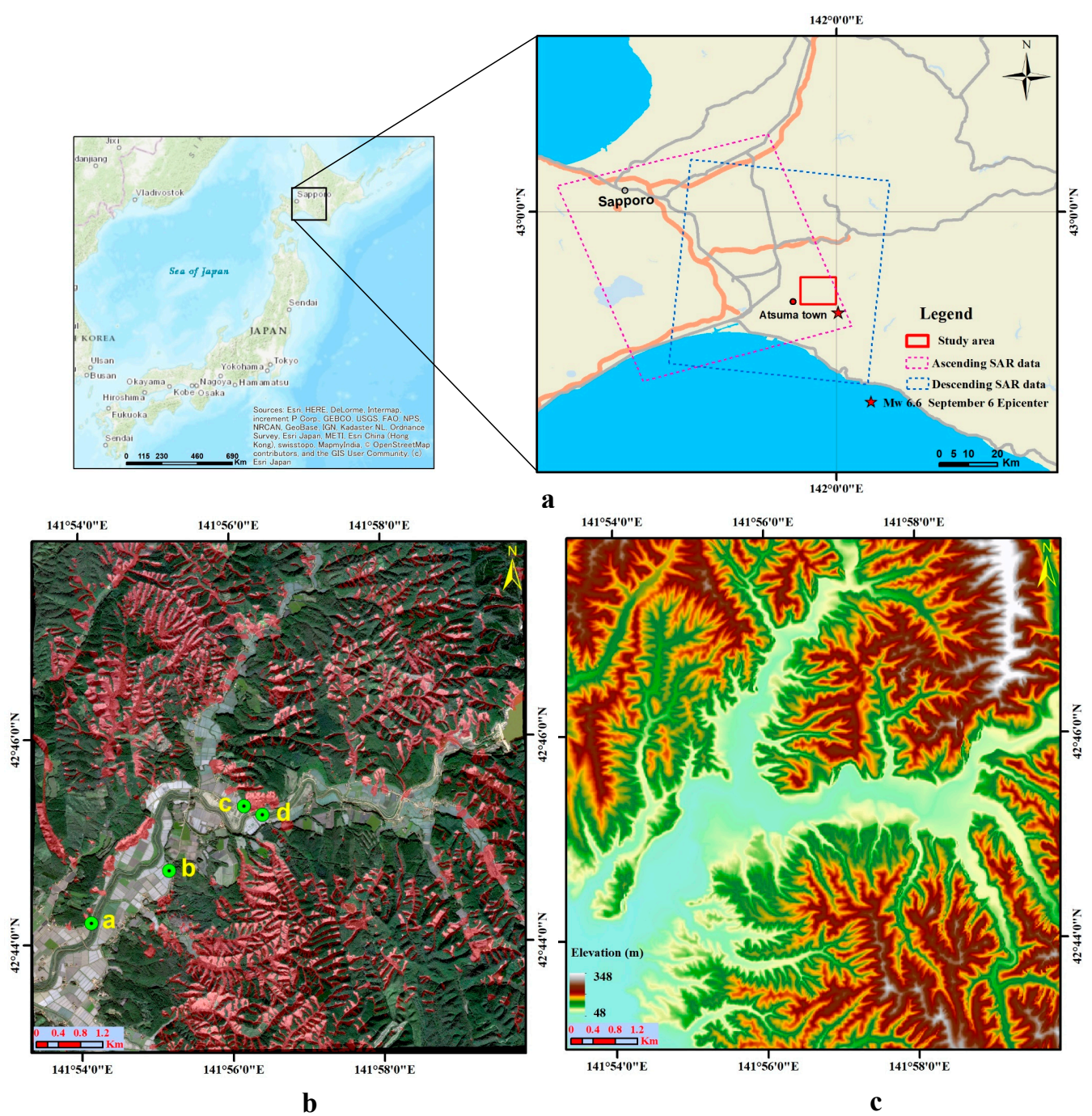

Figure 1. Map of the study area in Hokkaido, Japan: (a) the geographic location of the study area; (b) landslide areas identified by the GSI, Japan [23]; (c) the topography of the study area [28]. 
Four weeks after the earthquake, a field survey was carried out by the third and fourth authors on 3-4 October 2018 around Atsuma, Abira, and Mukawa towns. Figure 2 shows some ground photos of the landslides in Atsuma town. Figure 3 shows a land-use and land-cover (LULC) map of the study area. Deciduous broadleaf forest (DBF), deciduous needleleaf forest (DNF), rice paddy and grassland are the dominant classes in this area.
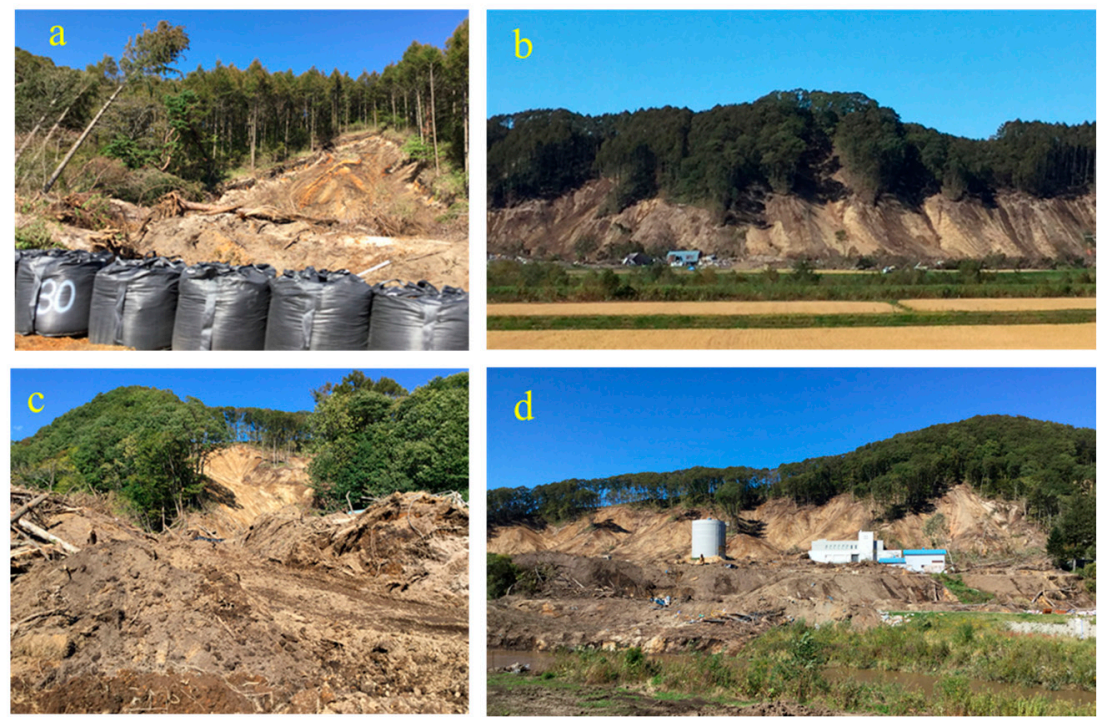

Figure 2. Field photographs of landslide areas in Atsuma town: (a) landslide along highway; (b) landslide hit houses in Yoshino district; (c) and (d) landslide hit water facility in Tomisato district. The approximate locations of those photos are indicated in Figure 1(b) as green circles.

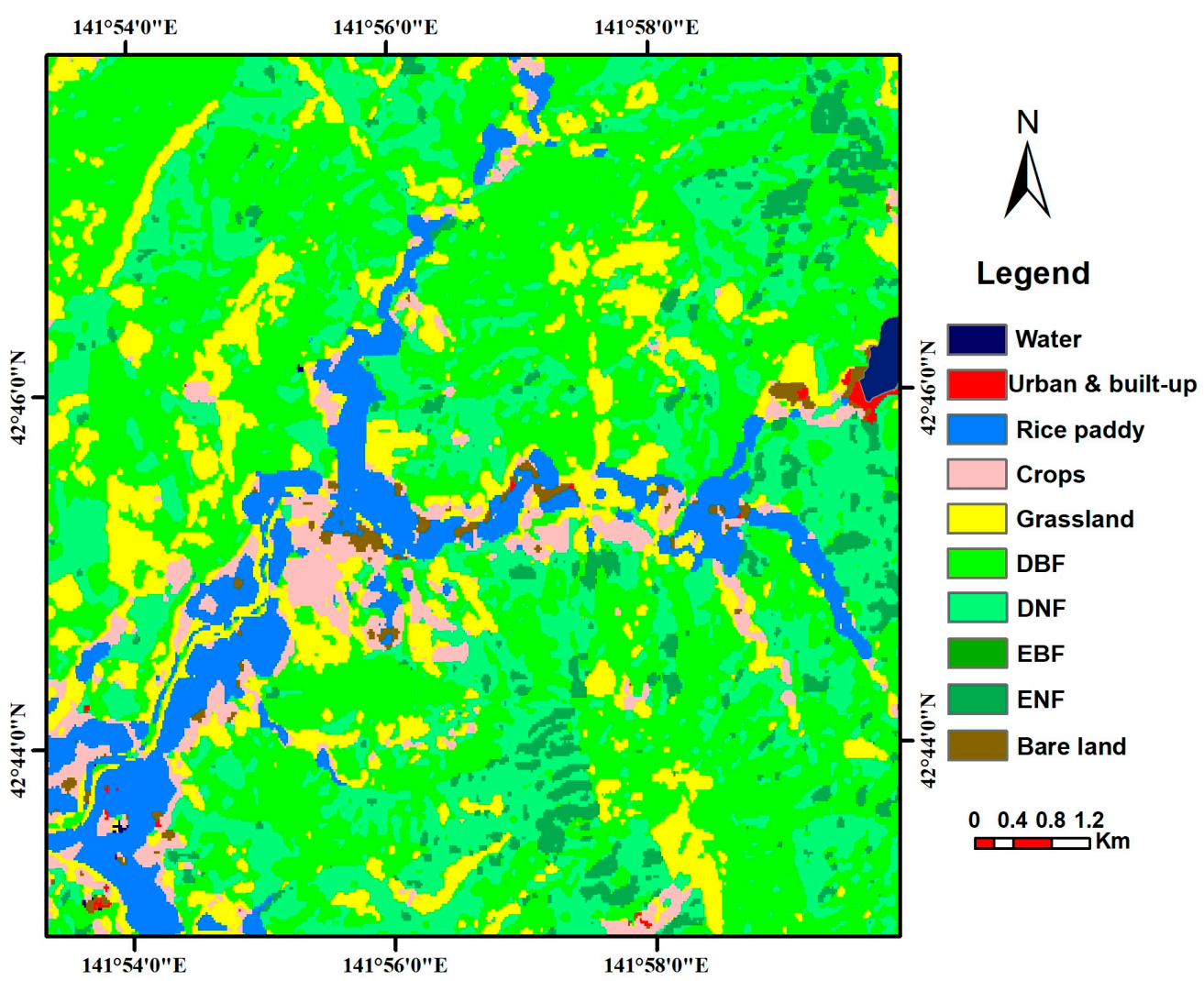

Figure 3. The land use and land cover maps of the study area. The data were provided by JAXA and are available at https://www.eorc.jaxa.jp/ALOS/en/lulc/lulc_index.htm. 


\section{Datasets}

In this study, L-band PALSAR-2 satellite datasets covering the region of interest (Figure 1), provided by the Japan Aerospace Exploration Agency (JAXA), were used. Table 1 summarizes the datasets. The interferometric coherence was computed from the single-look complex (SLC) PALSAR-2 data taken on 14 June 2018, 23 August 2018, and 06 September 2018 (descending) and on 09 August 2018, 23 August 2018, and 06 September 2018 (ascending). Both descending and ascending data are in stripmap (SM1) mode with $\mathrm{HH}$ polarization and with a high resolution of $3 \mathrm{~m}$. A $10 \mathrm{~m}$ high-resolution digital elevation model (DEM) provided by the GSI was used to co-register the Interferometric SAR (InSAR) pairs [28].

We also collected two high-resolution optical images from WorldView-2 and GeoEye-1, acquired on 24 October 2017 and 20 October 2018 with resolutions of $2 \mathrm{~m}$ (Figure 4). The optical images were used for visual comparison of landslide classification. To remove effects, such as the image perspective (tilt) and relief (terrain) effects, we orthorectified the image using the same $10 \mathrm{~m}$ DEM data that were used for the SAR data.
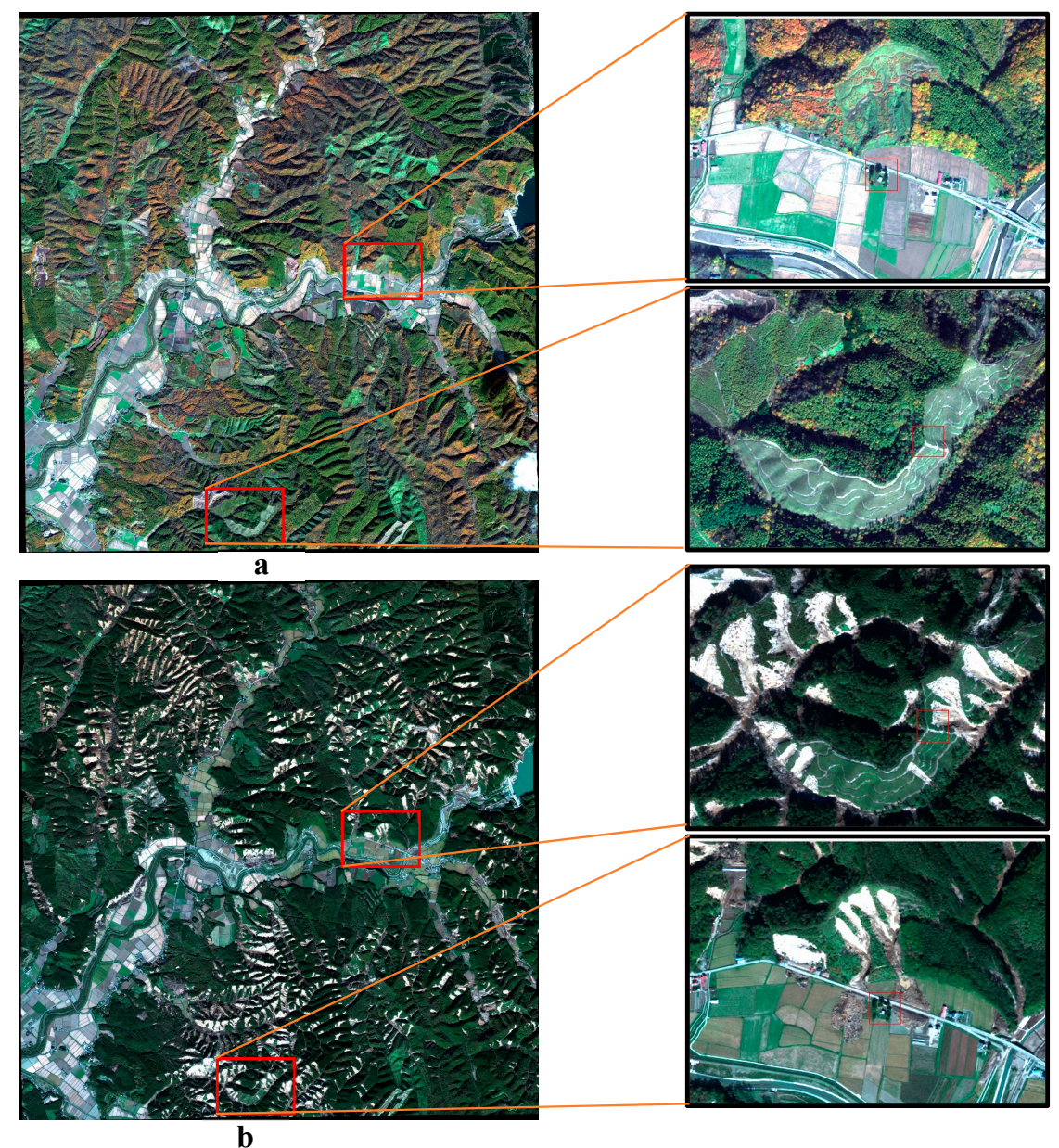

Figure 4. The orthorectified image from WorldView-2 (left) on 24 October 2017(a) and from GeoEye-1 (right) on 20 October 2018 (b); right Figures are the enlarged views of red rectangles in (a) and (b), respectively.

In this study, we used the landslide distribution map produced by the GSI, Japan [23], as the ground truth data (Figure 1b). According to the GSI, landslides were visually interpreted using high-resolution aerial photos taken on September 6, 8 and 11, 2018. The data are available on the website of GSI, Japan: http://www.gsi.go.jp/BOUSAI/H30-hokkaidoiburi-east-earthquake-index.html\#1. 
Table 1. Detailed information of the PALSAR-2 data. B, and $\mathrm{T}$ are normal baseline and temporal baseline, respectively. ${ }^{*}$ In both the ascending and descending datasets indicates the master image.

\begin{tabular}{lccccc}
\hline \multicolumn{1}{c}{ Date (UTC) } & Orbit & Polarization & Incidence & B (m) & T (days) \\
\hline (yyyy/mm/dd H:mm) & & Angle $\left(^{\circ}\right)$ & & \\
\hline 2018/06/14 02:40 & D 18 & HH & 36.2 & 237 & 70 \\
2018/08/23 02:40 & D 18 & HH & 36.2 & - & - \\
2018/09/06 02:40 & D 18 & HH & 36.2 & 69 & 14 \\
2018/08/09 13:37 & A 116 & HH & 42.9 & 68 & 14 \\
2018/08/23 13:37 * & A 116 & HH & 42.9 & - & - \\
2018/09/06 13:37 & A 116 & HH & 42.9 & 39 & 14 \\
\hline
\end{tabular}

\section{Methodology}

\subsection{Synthetic Aperture Radar: Interferometry and Coherence}

A radar interferogram can be calculated by using two SAR images acquired by the same satellite over the same region at different times [29]. Generally, an interferometric map (e.g., Figure 5b,d) shows the phase differences between two SAR images. The sequence of color fringes in the interferogram can be used to determine the change in distance between the satellite and the object (close or away). For ALOS-2 PALSAR-2, each color fringe shows the phase change of two images and is equal to one half of the wavelength of the PALSAR-2 sensor $(11.6 \mathrm{~cm})$.

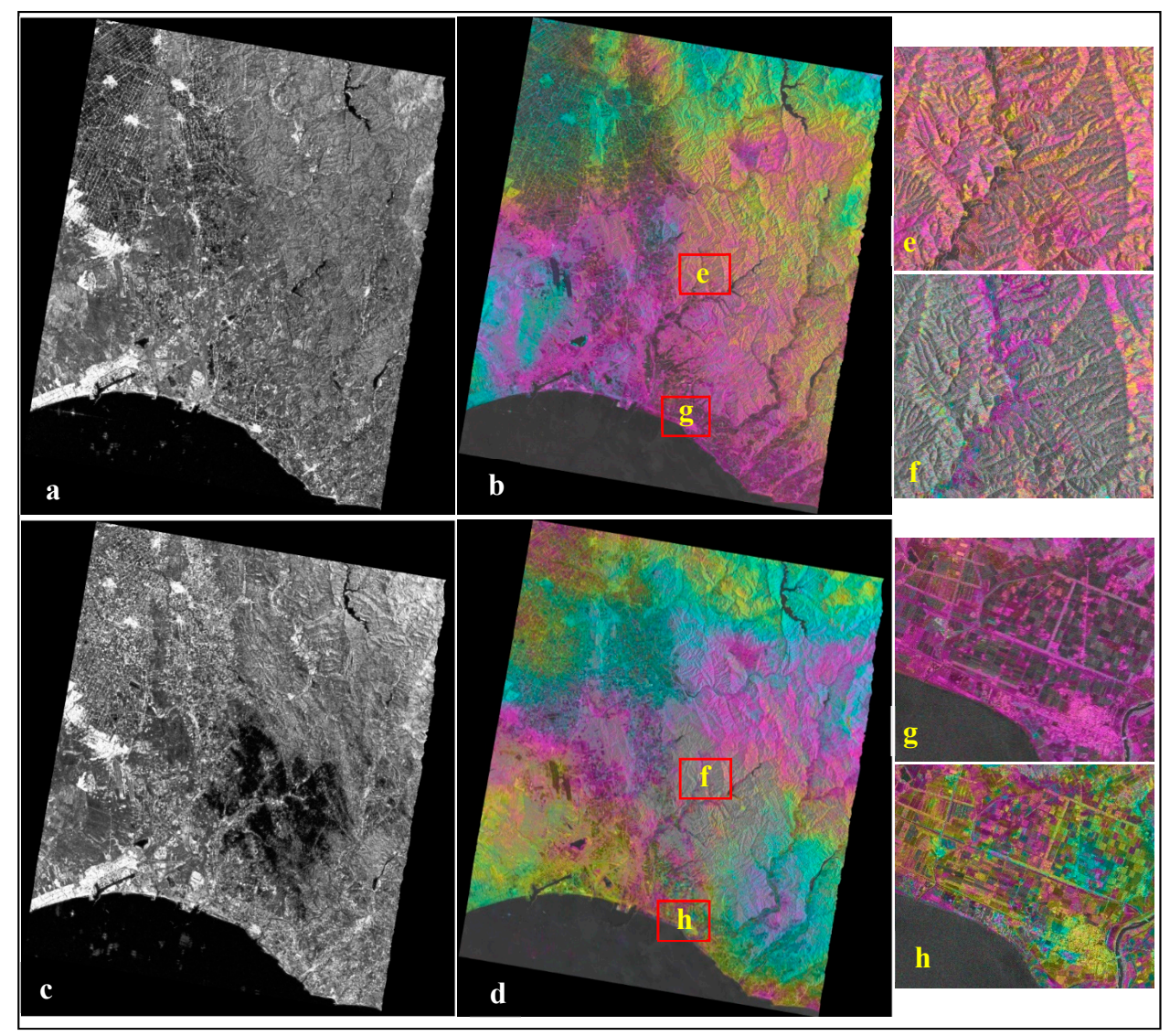

Figure 5. PALSAR-2 interferogram from pre-and co-event image pairs (descending). (a) and (b) are the coherence and interferogram of pre-event image pair (20180823-20180614); (c) and (d) are the coherence and interferogram of co-event image pair (20180823-20180906); (e-h) are the enlarged views of the preand co-event interferograms. 
The coherence $(\gamma)$ is the interferometric correlation of complex signals between two SAR data images, which can be calculated as:

$$
\gamma=\frac{\sum \mathrm{C}_{1} \mathrm{C}_{2}}{\sqrt{\sum\left|\mathrm{C}_{1}\right|^{2}} \sqrt{\sum\left|\mathrm{C}_{1}\right|^{2}}}
$$

where $\mathrm{C}$ is a complex number with phase $(\varphi)$ and amplitude $(A)$ [30].

Coherence is a normalized metric, and its values range from 0 to 1 . Coherence can be a good indicator of the quality of the interferogram, a high coherence value is associated with a 'good quality' interferogram and vice versa. Furthermore, coherence is sensitive to changes in either the phase or amplitude of a pixel. Therefore, ground surface changes due to earthquakes, landslides or flooding will alter the scattering properties of each pixel in SAR images and will result in low coherence [31]. As shown in Figure 5c,d, the coherence significantly decreased in the area where landslides occurred. Therefore, SAR coherence was used as the starting point in this study.

\subsection{SAR Coherence and Intensity Difference}

SAR has the capability of obtaining both amplitude and phase backscattering echoes from targets. The SAR products, such as SAR amplitude and coherence, can be complementary to each other for landslide mapping in highly vegetated regions [32]. Figure 6 shows both descending and ascending SAR coherence and intensity images and the corresponding landslide features on these images. The interferometric coherence map for both the ascending and descending PALSAR-2 data was generated by employing the SARscapeßModules (5.4) for ENVI (5.4) software suite (L3HARRIS Geospatial Solutions, Broomfield, CO, USA). For the original descending PALSAR-2 data, the SLC image from 23 August 2018, was selected as the master image, and the images from 14 June 2018, and 6 September 2018, were selected as slave images to generate two interferometric coherence images. For the original ascending PALSAR-2 data, the SLC image from 23 August 2018, was selected as the master image, and the images from 9 August 2018, and 6 September 2018, were selected as the slave images to generate two interferometric coherence images. Both descending and ascending coherence images were multi-looked by a factor of eight looks in azimuth and seven looks in range, giving a pixel size of approximately $15 \mathrm{~m}$. Multitemporal ANLD filtering [33] with a 3×3-pixel window was applied to the multi-looked coherence images and were geocoded in the WGS84 reference ellipsoid. For the descending and ascending intensity images, the same processes were performed and were geocoded to the same reference ellipsoid. The geocoded intensity images were calibrated to the normalized backscattering coefficients (sigma naught) using the equation:

$$
\sigma^{0}=10 \log _{10}\left\langle D N^{2}\right\rangle+C F_{1}
$$

where $\sigma^{0}$ is the backscattering coefficient (unit: $\mathrm{dB}$ ), $D N$ is digital number of SAR amplitude images, and $C F_{1}$ is the calibration factor $(-83 \mathrm{~dB})$.

Speckle noise reduction is a crucial step for SAR applications. For the final geocoded products, we applied the same enhanced Lee filter with $5 \times 5$ window size for both the coherence and intensity images. Additionally, we calculated the differences between the pre- and co-event coherence and between the pre- and post-event intensity images as shown in Figure 6. 


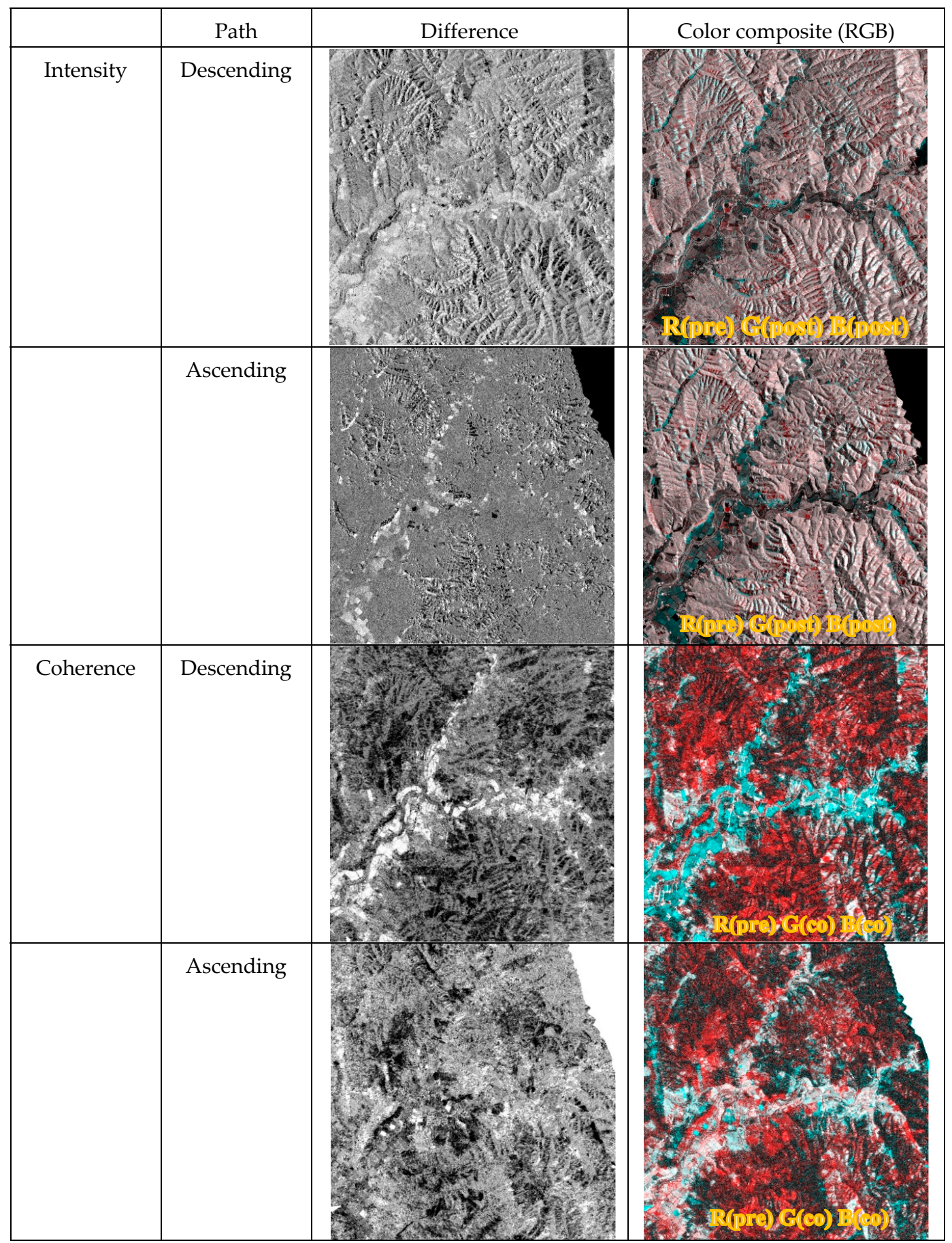

Figure 6. The differences in synthetic aperture radar (SAR) intensities and coherence and the color composite map of the study area. The intensity/coherence differences were calculated by subtracting the pre-event values from the post-event/co-event values.

The SAR amplitude and phase are sensitive to earth-surface properties, such as changes in height, roughness and moisture content. As shown in Figure 3, almost 95\% of the study area is covered by vegetation. Generally, landslides replace vegetated areas with bare soils or rocks. This phenomenon alters the scattering properties of each pixel in SAR images spanning landslide events and leads to low temporal coherence. Pixels in landslides are expected to exhibit low coherence, as shown in the images in Figure 6. Therefore, interferometric coherence can be used to map landslides [7]. However, interferometric coherence is affected by temporal and spatial baselines. Since the study area is heavily 
vegetated, the low coherence may also have been caused by seasonal changes or moister vegetation, which may have led to many false positives in landslide classification. This phenomenon is evident in Figure 6. Cropland and grassland areas also exhibited low coherence as for the landslides in the ascending coherence difference. The SAR intensity is sensitive to the roughness and slope of the ground surface and is less affected by the temporal and spatial baselines. Figure 6 shows the preand post-event intensity differences and the color composite image. Landslides generally change the vegetation and topography, thus altering the intensities of the backscattered waves. The removal of trees leads to decreases in the image intensities, and the accumulated debris leads to increases in intensity (Figure 6). Therefore, the intensity differences can be used for landslide identification [32].

Landslide detection using SAR coherence and intensity images is affected by foreshortening, layover, and shadowing, since radar measures the distances to features as the slant-range. These factors reduce the accuracy of the landslide classifications by adding commission and omission errors. SAR data from different orbits (i.e., descending and ascending) can be good complements to each other when they are available. Therefore, we have examined the applicability of coherence and intensity for both descending and ascending orbits. The comparison results are described in Section 5.

\subsection{Statistical Methods}

Statistical methods refer to the use of the statistical parameters of the mean $(\mu)$ and the standard deviation $(\sigma)$ to calculating a threshold by $\mu \pm k \sigma$, where $k$ is an empirical parameter set by the user that can be adjusted [34]. In this method, the density function of the continuous change image is almost equal to the density function of the unmodified pixels and, in the determination of the threshold has statistically fixed [35].

The intensity differences in the ascending and descending pairs show both increase and decrease in landslide pixels. Therefore, the optimal threshold for the intensity difference was determined by the criteria, $\Delta \operatorname{Int}<\left(\mu-k_{1} \sigma\right)$ or $\Delta \operatorname{Int}>\left(\mu+k_{2} \sigma\right)$, where $k$ is the threshold coefficient value and can be adjusted according to the histogram. For the coherence difference, most landslides show a significant decrease in coherence, while croplands and grasses show an increase in coherence (Figure 6). Therefore, only the left threshold criteria, $\Delta C o h<(\mu-k \sigma)$ was used for the coherence differences.

\subsection{Decision Tree Classification}

The decision tree (DT) classification technique was adopted to map landslides by using pre- and post-event PALSAR-2 images. The decision tree classifier is a type of multistage classifier that can be applied to a single image or to a stack of images. Because of its simplicity, flexibility, and computational efficiency, it has been widely used in many studies $[36,37]$. The decision tree scheme is built based on inputs from pre- and co-event coherence differences, pre- and post-event intensity difference images, DEMs, and slopes. Through the analysis of the nature of landslides, and the topography of the study area, we established a decision tree-based classification scheme as described in Figure 7. 


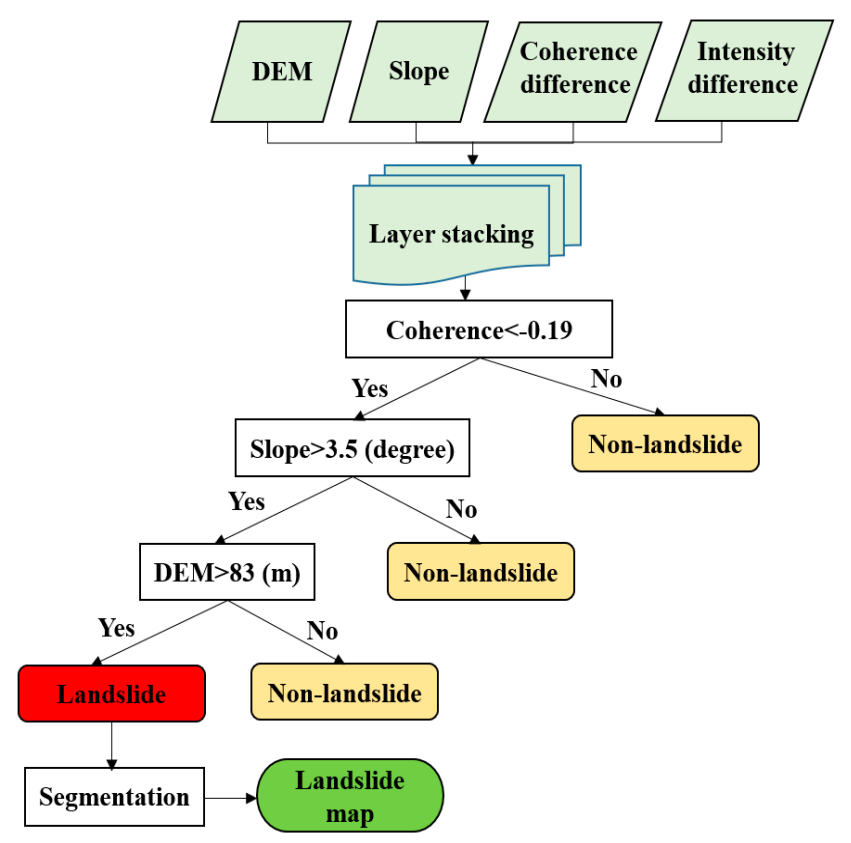

Figure 7. The scheme for the decision tree-based landslide mapping. Coherence and intensity differences refer to both the descending and ascending paths.

\section{Results}

\subsection{Landslide Classification Using Descending and Ascending SAR Images}

The intensity and coherence are sensitive to changes of the ground surface; therefore, they can provide useful information for landslide detection. However, the performances of these products in identifying landslides might vary depending on the SAR acquisition conditions to some extent. Therefore, we tried six different combinations: (1) Using only the coherence differences in the descending paths; (2) using only the intensity differences in the descending paths; (3) using both the coherence and intensity differences in the descending paths; (4) using the coherence differences in both the descending and ascending paths; (5) using the intensity differences in both the descending and ascending paths; and (6) using both the coherence and intensity differences in both the descending and ascending paths.

In case 1, the coherence difference in the descending paths (pre-event:20180823-20180614 and co-event:20180823-20180906) was used. According to Shimada [38], the coherence is dependent on the incidence angle, and the increase in incidence angle will result the decrease in coherence. As shown in Table 1, the descending data has smaller incidence angle, and the initial processing result of descending path was much better than that of ascending path (Figure 6). Therefore, we used the only descending case. First, the DEM and slope were resampled to the same ground resolution as the SAR coherence $(15 \mathrm{~m})$, and the datasets were layer-stacked. The optimal threshold values for the coherence difference were determined by the statistical method (based on the calculated mean and standard deviation values). Then, a natural-break classification method was used to classify the slope using ArcGIS. In the first step, the input image pixels were divided into two groups: landslide and non-landslide based on the coherence difference $(\mu=-0.12, \sigma=0.13$, and $k=0.5)$ threshold of $\Delta$ Coh $=-0.19$. In the second step, the pixels filtered through the above criterion were then divided into landslide and non-landslide by a slope threshold of 3.5 degrees. In the third step, the remaining pixels classified as landslides were divided into landslide and non-landslide using the DEM threshold value of $83 \mathrm{~m}$. Finally, to remove the isolated noisy pixels, the classified image was segmented (the number of neighbors was 8 , and the minimum population was 30 pixels) into regions of connected pixels that were contained in the same class. The final classification result is shown in Figure 8, where the red pixels represent the classified 
landslides. We overlaid them on the optical GeoEye-1 image taken on 20 October 2018 for better visual inspection (transparency of $70 \%$ was set to the landslide pixels).

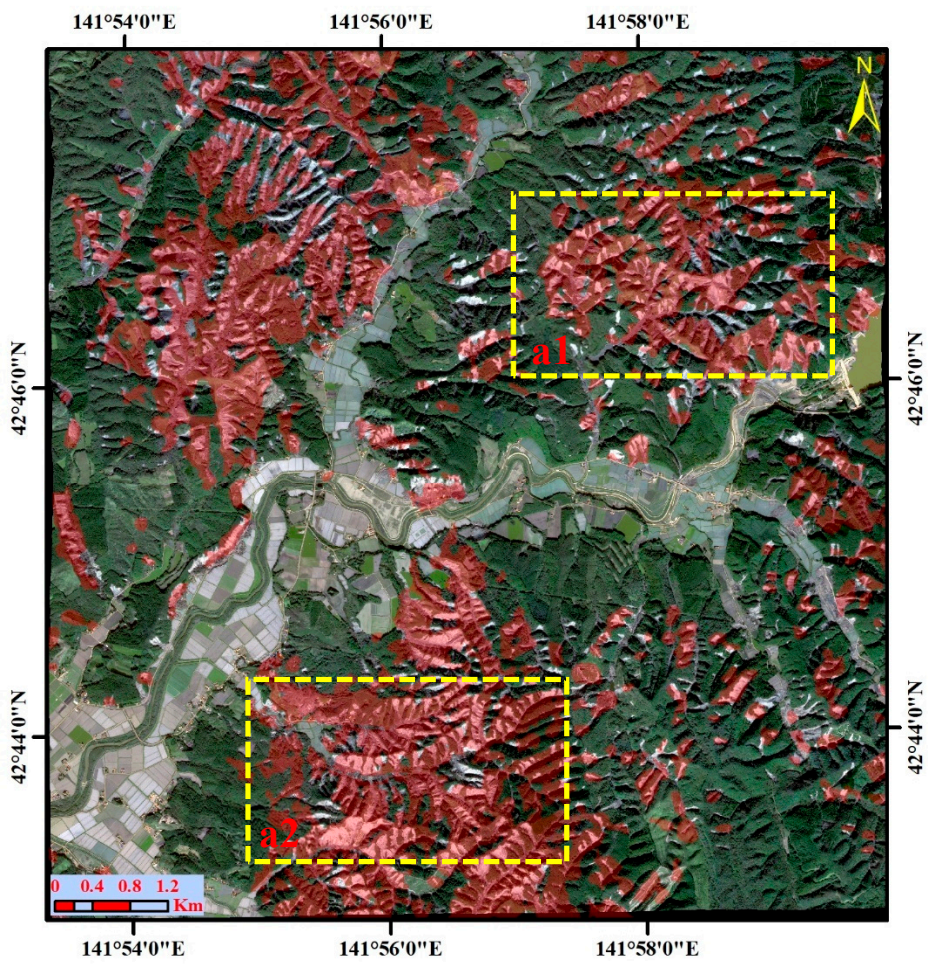

Figure 8. The landslide classification map using only the descending SAR coherence (case 1).

The background is a GeoEye-1 image taken on 20 October 2018.

For assessing the accuracy of classification results, we compared these results with the high-resolution optical images from WorldView-2 and GeoEye-1. As shown in Figure 9, most landslides were effectively detected by the proposed method. However, some small- and medium-scale landslides, indicated by yellow circles and rectangles, were omitted and classified as non-landslides (Figure 9c1). Moreover, in Figure 9c2, a very large landslide was also misclassified as a non-landslide. This result may be related to the geometry of SAR image. We used the PALSAR-2 images in the descending track (west-facing sensor), and the slopes facing away from the sensor (steep, west-facing slopes) were not well imaged. Moreover, the quality of the coherence (e.g., geometrical, temporal decorrelations, and atmospheric noise) may also have hindered the full use of coherence values.

In case 2, we examined the performance of SAR intensity for landslide mapping. We used the pre-event (2018089) and post-event (20180906) PALSAR-2 intensity images in the descending path and calculated their differences by subtracting the pre-event values from the post-event values. The same decision tree classification procedure was used with intensity threshold criteria of $\Delta \operatorname{Int}<-2.13 \mathrm{~dB}$ and $\Delta$ Int $>1.91 \mathrm{~dB}\left(\mu=-0.78, \sigma=2.70, k_{1}=0.5\right.$ for the left threshold and $k_{2}=1.0$ for the right threshold). Then, the same threshold criteria for the slopes and for the DEM were also used in this step to remove the classified landslides in flat areas. The classification results were segmented to remove small speckles classified as landslides. The final classification results are shown in Figure 10. We can see that the intensity-based classification shows a quite satisfactory result, especially in the area in red rectangle which was not identified in case 1 . However, many landslides were still not fully extracted by this method. 

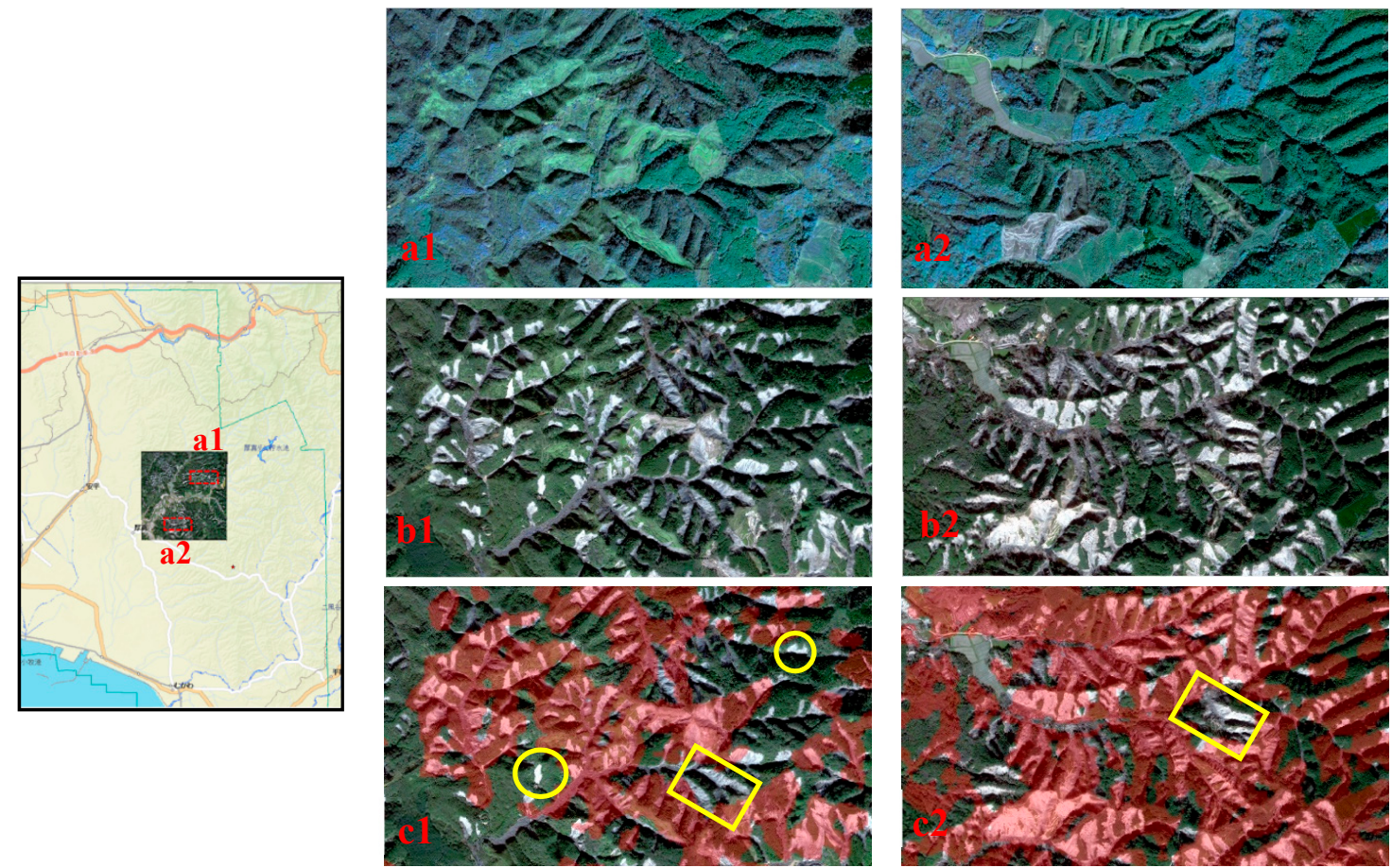

Figure 9. Visual comparison of classification results (case 1) with the pre- and post-event high-resolution optical images. a1 and a2 are from WorldView-2 taken on 24 October 2017; (b1 and b2) are from GeoEye-1 image taken on 20 October 2018; c1 and c2 are the identified landslides overlaid on the GeoEye-1 image.

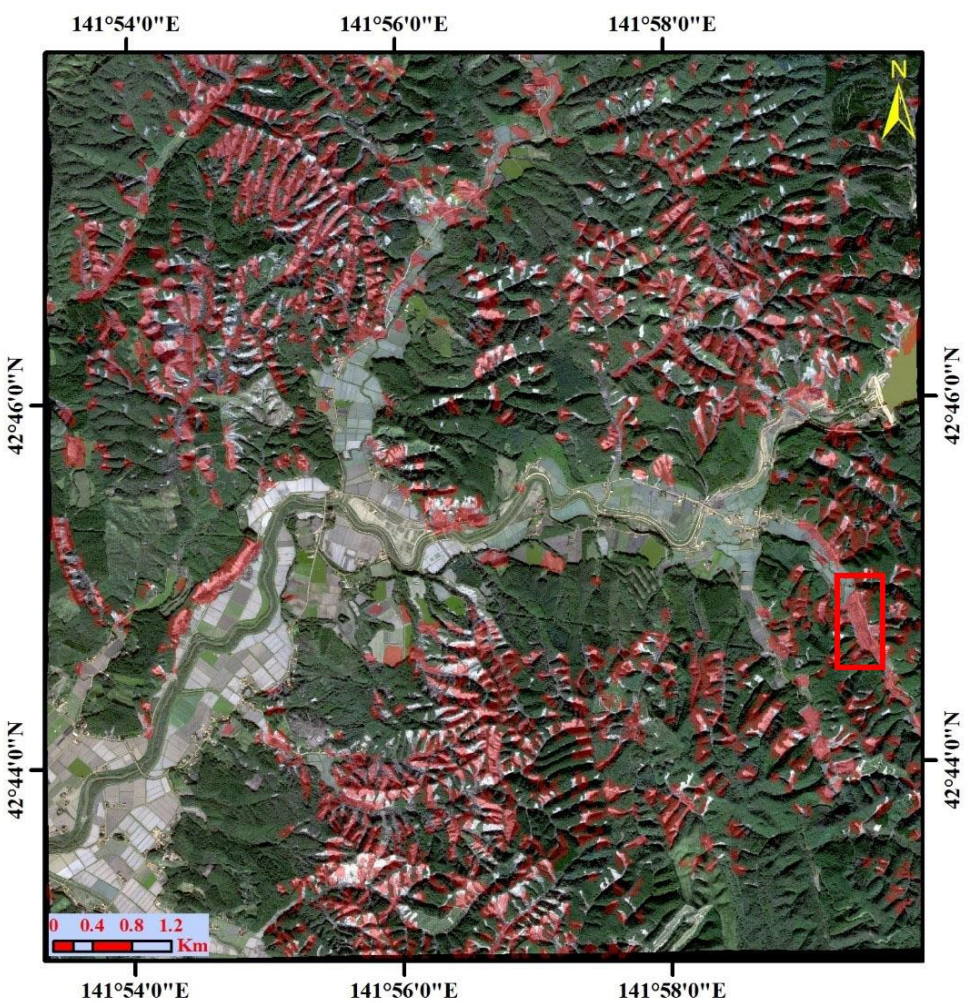

Figure 10. The landslide classification map using only the descending SAR intensity (case 2). The background is a GeoEye-1 image taken on 20 October 2018. 
In case 3, to improve the landslide classification results, we used both the PALSAR-2 coherence and intensity difference images in the descending path. The same decision tree classification procedure was used, while the intensity difference range $\Delta \operatorname{In} t<-2.13 \mathrm{~dB}$ or $\Delta I n t>1.91 \mathrm{~dB}$ were added to the coherence difference threshold $\Delta C$ oh $<-0.19$ in the main node. Then, the same threshold for slope and DEM were also used in this step to remove the flat areas classified as landslides. The same segmentation criteria were used to remove the classified landslides in the flat areas. The final classification result is shown in Figure 11. We can see that, by using the coherence and intensity differences, the possibility of correctly identified landslides has increased significantly. However, the commission errors (false positive), e.g., grassland and cropland classified as landslides, also increased.

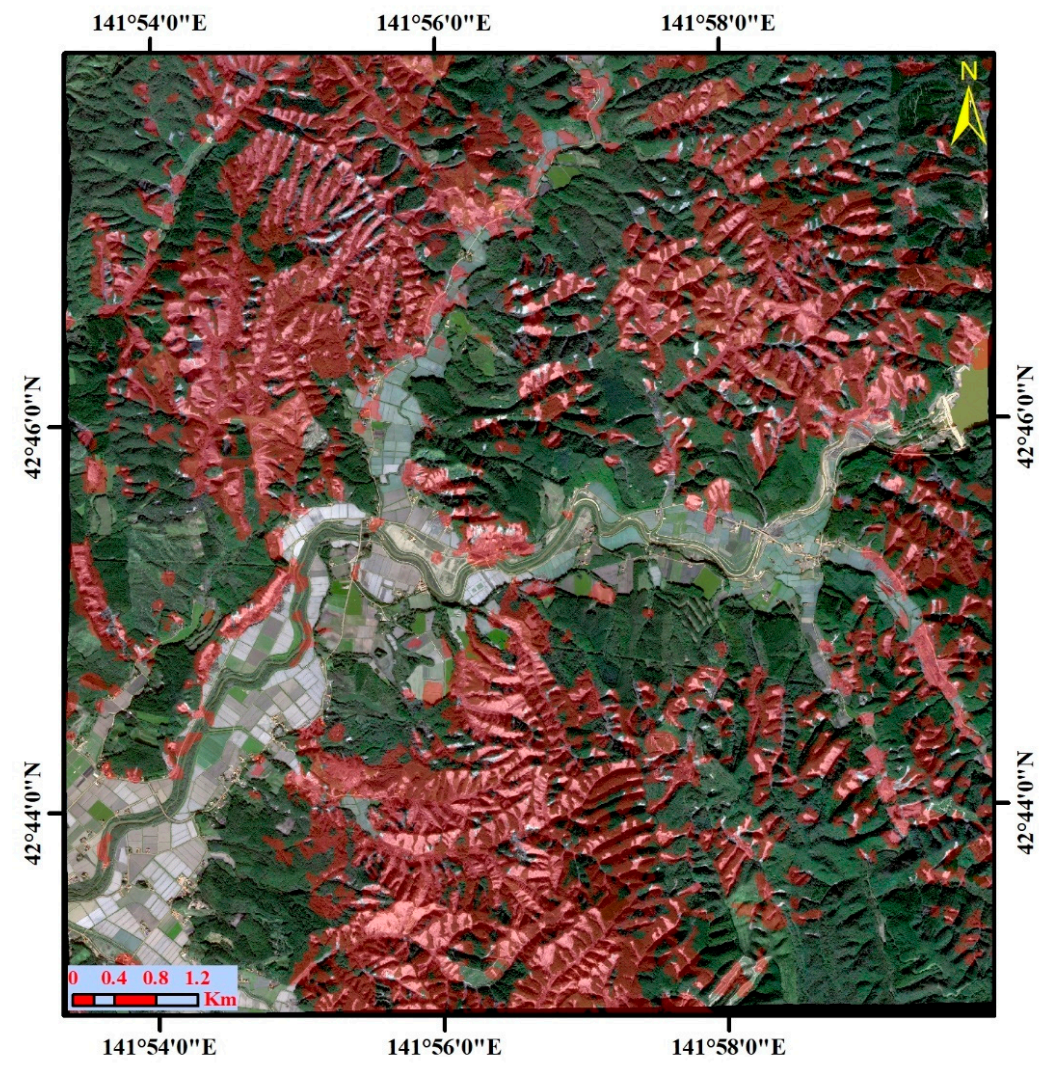

Figure 11. The landslide classification map using both coherence and intensity difference in descending SAR images (case 3). The background is a GeoEye-1 image taken on 20 October 2018.

In cases 4 and 5, we attempted to use both the PALSAR-2 coherence and intensity difference in the descending and ascending paths, respectively. In case 4 , for the use of PALSAR-2 ascending and descending coherence, the same decision tree classification procedure used for the descending coherence was used, and the coherence difference threshold was $\Delta$ Coh $<-0.18(\mu=-0.117, \sigma=0.122$, $k=0.5)$ for ascending or $\Delta C o h<-0.19$ for descending in the main node.

In case 5 , for the use of PALSAR-2 ascending and descending intensity, the intensity difference threshold was $\Delta I n t<-2.13 \mathrm{~dB}$ or $\Delta \operatorname{Int}>1.91 \mathrm{~dB}$ for descending or $\Delta \operatorname{Int}<-1.64 \mathrm{~dB}$ or $\Delta \operatorname{Int}>2.83 \mathrm{~dB}$ for ascending $(\mu=0.593, \sigma=2.232, k=1.0)$ in the main node. Then, the same thresholds for slope and DEM were also used to exclude the classified landslides in flat areas. After segmentation, the final classification results are shown in Figures 12 and 13. From these Figures, we can see that, by adding the ascending coherence and intensity to the descending pairs, the correctly identified landslides increased. The use of both the descending and ascending coherence tends to overestimate the landslides. However, the use of both the descending and ascending intensities shows a better result than the coherence with fewer commission errors. 


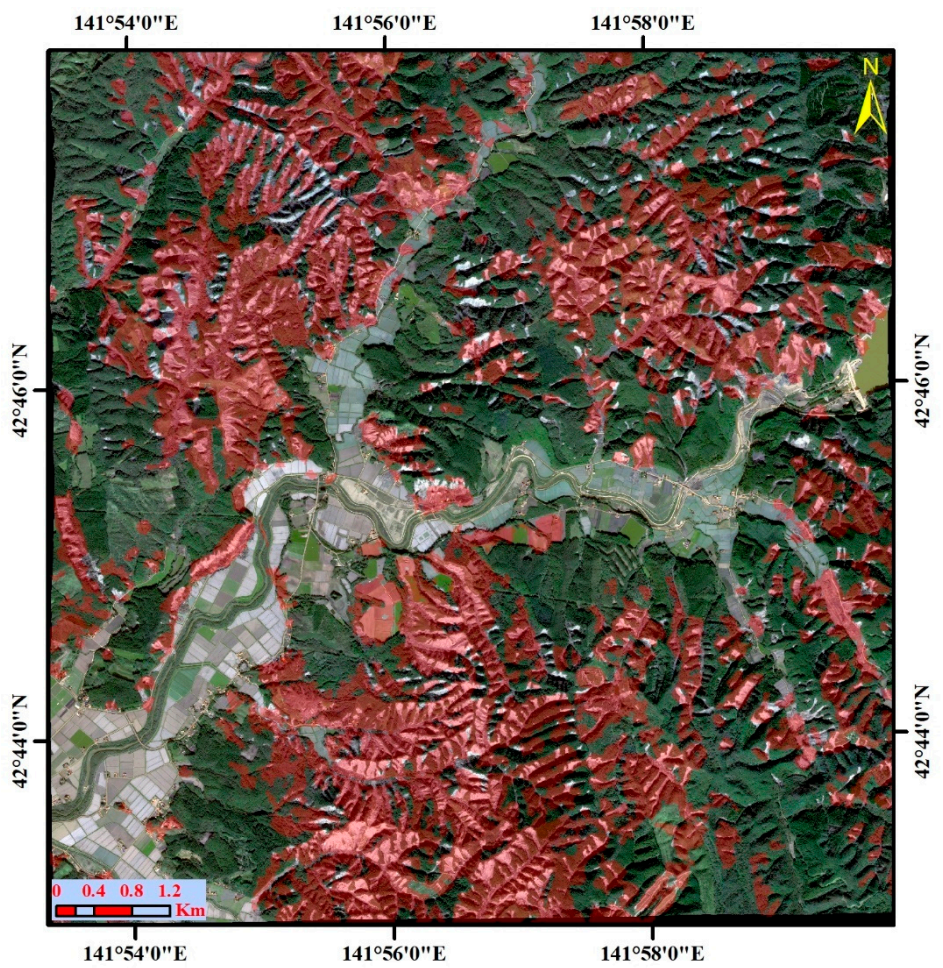

Figure 12. The landslide classification map using the coherence differences in both descending and ascending SAR images (case 4). The background is a GeoEye-1 image taken on 20 October 2018.

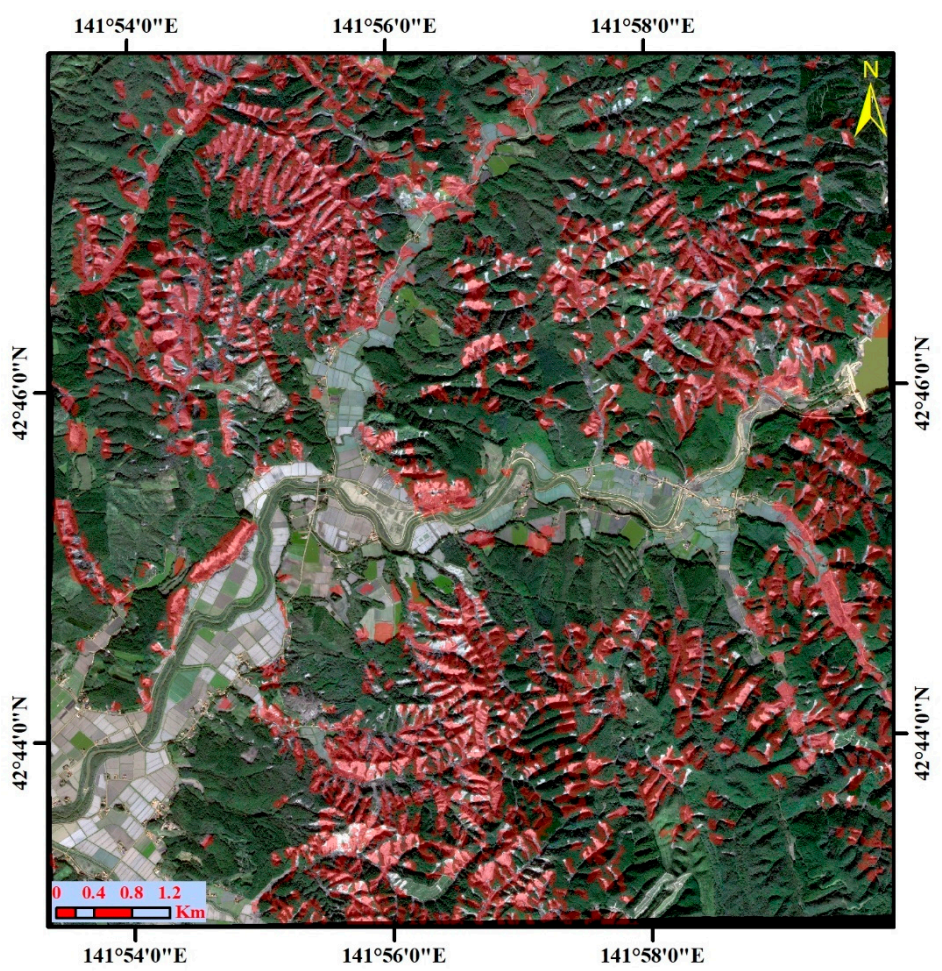

Figure 13. The landslide classification map using intensity differences from both the descending and the ascending SAR images (case 5). The background is a GeoEye-1 image taken on 20 October 2018.

In case 6, we have used all the available SAR coherence and intensity differences in both the descending and ascending paths. The image processing was based on the threshold criteria used in the previous steps. The same segmentation criteria were also used to remove small speckles classified 
as landslides. The final classification result is shown in Figure 14. We can see that almost all the landslides were identified by this method. However, as shown by the yellow rectangle in the Figure 14, the possibility of non-landslide areas being classified as landslides also increased. The vegetation changes between the two SAR acquisitions may have resulted in significant modifications to the ground surface. Therefore, further consideration must be taken to reduce the uncertainties caused by vegetation changes.

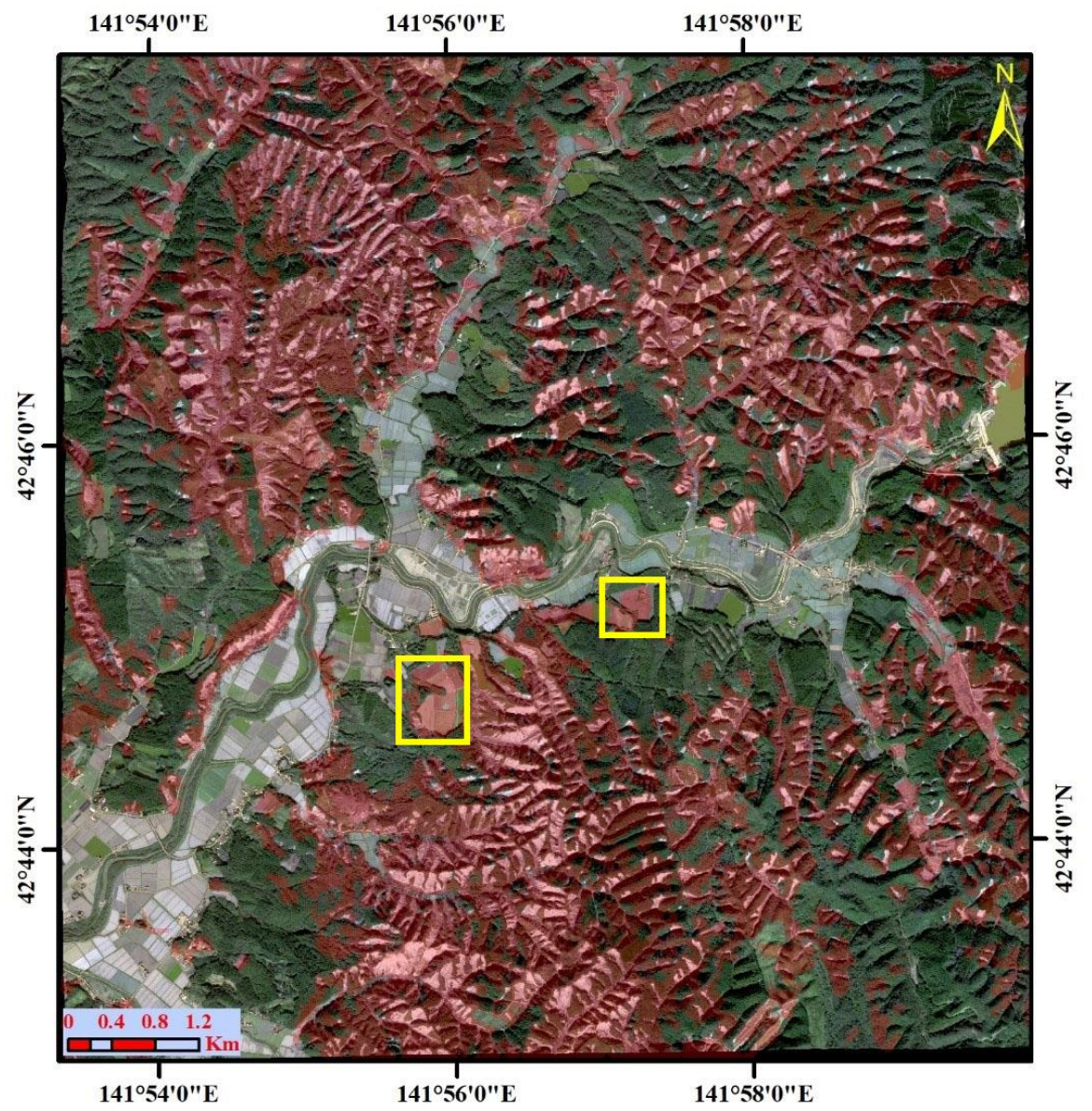

Figure 14. The landslide classification map using coherence and intensity differences from both descending and ascending SAR pairs (case 6). The background is a GeoEye-1 image taken on 20 October 2018.

\subsection{Quantitative Analysis of the Landslide Classification Accuracy}

To evaluate the performance of the six different combinations for landslide mapping, we compared the detected landslides with the polygon data of the landslides released by GSI, Japan [23]. Before the comparison, we converted the classification results in raster format to vectors as presented by the GSI (shapefiles). We also used the intersect tool in the analysis toolbox of ArcGIS 10.3.1 software, and calculated the correctly classified landslides comparing with the landslide truth data. We then computed the class statistics and confusion metrics for the six different combinations as shown in Table 2.

For case 1, using only the descending SAR coherence, we see that the total estimated landslide area was $10.39 \mathrm{~km}^{2}$, which was $55.9 \%$ of the total landslide area in the ground truth data. The overall accuracy and kappa coefficient were $75.38 \%$ and 0.34 , respectively. The descending SAR intensity-based classification (case 2) identified fewer landslides $\left(8.71 \mathrm{~km}^{2}\right)$ but with a smaller commission error than the coherence-based classification (54\% UA). The overall accuracy and kappa coefficient were 79.47\% and 0.38 , respectively. The descending SAR coherence and intensity-based landslide classification 
(case 3) showed an increase in landslide identification to a total of $14.05 \mathrm{~km}^{2}$. However, the commission error also increased and led to lower overall accuracy $(74.83 \%)$ than for the sole use of coherence.

Table 2. The results of accuracy assessment of landslide classifications (case 1-6). UA and PA refer to the user's and producer's accuracies, respectively.

\begin{tabular}{|c|c|c|c|c|c|}
\hline & & \multicolumn{4}{|c|}{ Ground Truth Data } \\
\hline & & $\begin{array}{c}\text { Landslides } \\
\quad\left(\mathbf{k m}^{2}\right)\end{array}$ & Others $\left(\mathrm{km}^{2}\right)$ & Total $\left(\mathrm{km}^{2}\right)$ & UA (\%) \\
\hline \multirow{4}{*}{$\begin{array}{c}\text { Classified } \\
\text { Case } 1\end{array}$} & Landslides & 13.39 & 12.34 & 22.72 & 45.72 \\
\hline & Others & 8.20 & 52.49 & 60.70 & 86.49 \\
\hline & Total & 18.59 & 64.83 & 83.42 & \\
\hline & PA (\%) & 55.87 & 80.97 & & \\
\hline \multicolumn{2}{|c|}{ Overall Accuracy } & $75.38 \%$ & \multicolumn{2}{|c|}{ Kappa Coefficient } & 0.34 \\
\hline \multirow{4}{*}{$\begin{array}{c}\text { Classified } \\
\text { Case } 2\end{array}$} & Landslides & 8.71 & 7.16 & 15.87 & 54.89 \\
\hline & Others & 9.88 & 57.67 & 67.55 & 85.37 \\
\hline & Total & 18.59 & 64.84 & 83.42 & \\
\hline & PA (\%) & 46.86 & 88.96 & & \\
\hline \multicolumn{2}{|c|}{ Overall Accuracy } & $79.57 \%$ & \multicolumn{2}{|c|}{ Kappa Coefficient } & 0.38 \\
\hline \multirow{4}{*}{$\begin{array}{c}\text { Classified } \\
\text { Case } 3\end{array}$} & Landslides & 14.05 & 16.46 & 30.51 & 46.06 \\
\hline & Others & 4.54 & 48.38 & 52.91 & 91.42 \\
\hline & Total & 18.59 & 64.83 & 83.42 & \\
\hline & PA (\%) & 75.58 & 74.55 & & \\
\hline \multicolumn{2}{|c|}{ Overall Accuracy } & $74.83 \%$ & \multicolumn{2}{|c|}{ Kappa Coefficient } & 0.41 \\
\hline \multirow{4}{*}{$\begin{array}{l}\text { Classified } \\
\text { Case } 4\end{array}$} & Landslides & 126.2 & 16.99 & 29.61 & 42.61 \\
\hline & Others & 5.97 & 47.84 & 53.81 & 88.89 \\
\hline & Total & 18.59 & 64.83 & 83.42 & \\
\hline & PA (\%) & 67.86 & 73.79 & & \\
\hline \multicolumn{2}{|c|}{ Overall Accuracy } & $72.47 \%$ & \multicolumn{2}{|c|}{ Kappa Coefficient } & 0.34 \\
\hline \multirow{4}{*}{$\begin{array}{l}\text { Classified } \\
\text { Case } 5\end{array}$} & Landslides & 11.50 & 9.50 & 21.00 & 54.77 \\
\hline & Others & 7.09 & 55.33 & 62.42 & 88.65 \\
\hline & Total & 18.59 & 64.83 & 83.42 & \\
\hline & PA (\%) & 61.87 & 85.35 & & \\
\hline \multicolumn{2}{|c|}{ Overall Accuracy } & $80.12 \%$ & \multicolumn{2}{|c|}{ Kappa Coefficient } & 0.45 \\
\hline \multirow{4}{*}{$\begin{array}{c}\text { Classified } \\
\text { Case } 6\end{array}$} & Landslides & 16.01 & 20.98 & 36.99 & 43.28 \\
\hline & Others & 2.58 & 43.85 & 46.43 & 93.60 \\
\hline & Total & 18.59 & 64.83 & 83.42 & \\
\hline & PA $(\%)$ & 86.12 & 67.64 & & \\
\hline \multicolumn{2}{|c|}{ Overall Accuracy } & $71.75 \%$ & \multicolumn{2}{|c|}{ Kappa Coefficient } & 0.39 \\
\hline
\end{tabular}

The descending and ascending coherence-based classification led to more commission errors for landslides, for which $16.99 \mathrm{~km}^{2}$ out of $29.61 \mathrm{~km}^{2}$ were misclassified as landslides in case 4 . The overall accuracy and kappa coefficient were $72.47 \%$ and 0.34 , respectively. The descending and ascending intensity-based classification (case 5) showed a better result than did the coherence, and the accurately-classified landslides totaled $11.5 \mathrm{~km}^{2}$, representing $62 \%$ of the actual landslides. The overall accuracy and Kappa coefficient were $80.12 \%$ and 0.45 , respectively. The results from the use of the descending and ascending pairs' intensity and coherence (case 6) increased the possibility of landslide identification, and the correctly classified landslides totaled $16.01 \mathrm{~km}^{2}$ of the $18.59 \mathrm{~km}^{2}$ area of actual landslides (86.12\%). However, the commission errors also increased accordingly. $20.98 \mathrm{~km}^{2}$ were misclassified as landslides. The overall accuracy and kappa coefficient were $71.75 \%$ and 0.39 , respectively.

The quantitative comparison results show that the descending and ascending intensity-based classification (case 5) has the best overall accuracy and a kappa coefficient with fewer commission errors. 
The coherence was low in highly vegetated areas even without the earthquake. The geometrical and temporal decorrelations also hindered the applicability of coherence, which showed more commission errors and led to a lower overall accuracy for the classification.

\section{Discussion}

In this study, we investigated the potential of SAR coherence and intensity for detecting earthquake-induced landslides from PALSAR-2 images. As the side-looking geometry of SAR systems causes geometric distortions (e.g., layover and radar shadow), identical acquisition geometries for SAR imagery are required for change detection applications [6,39]. Thus, we used both the ascending and descending PALSAR-2 imagery to maximize the area that can be mapped. We found that the SAR backscattering intensity is more suitable than the coherence for landslide identification. However, Burrows et al. [7] detected the Nepal earthquake-induced landslide using SAR coherence and found that the SAR coherence methods were more successful for landslide detection at lower spatial resolutions. These authors also indicated that SAR amplitude methods are likely to perform better in highly vegetated regions. This finding may be consistent with our results, as almost $95 \%$ of the study area was covered by vegetation. In addition, although we mainly focused on the use of the intensity difference, the combined use of the SAR intensity correlation and optical images also showed a promising result in building damage estimation [40]. Matsuoka and Yamazaki [41] developed an automated method that uses the correlation and difference in the SAR backscattering coefficient as variables to detect hard-hit urban areas based on the linear discriminant analysis. We also tested the SAR intensity correlation in our initial analysis on the descending data but found it to be outperformed by intensity-based classifiers, so did not report it here. However, a further research is needed to evaluate the applicability of the combined use of the intensity correlation and difference in earthquake-induced landslide detection.

In general, the interferometric coherence is more sensitive to small changes caused by severe damage compared to the SAR intensity, and can be successfully applied to detect the earthquake/rainfall induced landslides $[7,15,17]$. However, there are certain obstacles exist in the pre-processing. The SAR acquisition geometry affects the quality of images over mountainous areas where landslides are likely to occur, and hence the use of SAR signals in a traditional statistical classification approach becomes difficult mainly due to speckling [16]. Moreover, both the SAR intensity-based and coherence-based methods used in this study are partially/highly dependent on the satellite geometry, wavelengths, and temporal baseline. Thus, the applicability of the methods used in this study might be hindered if both the ascending and descending data pairs are not available. Besides the intensity and coherence, the use of SAR polarimetry, polarimetric decomposition and the synergetic use of optical and polarimetric SAR data are also showed effectiveness in landslide detection [6,42-44]. As each method has advantages and shortcomings when selecting a method for landslide detection purpose, the priority must be given based on the availability of SAR data, geographic conditions of the target area, and the nature of the landslide.

The detection of landslides by using measures of the changes between pre- and post-event SAR amplitude images is based on the assumption that landslide occurrences change the local land cover and some of its properties (e.g., roughness and moisture content) [16,45]. However, such land cover changes can be triggered not only by landslides but also by human activities, such as the cultivation of flatlands. As shown in Figure 15, considering the whole SAR coverage area, quick identification of landslides can be accomplished using the color composite of coherence pairs (Figure 15a). For the intensity, however, not only the landslides (mostly shallow landslides [21]) but also the cropland areas showed significant changes in the pre- and post-event intensity color composite (Figure 15c). Therefore, we employed the slope data to filter out the detected land cover changes other than landslides. Several researchers have also shown the effectiveness of slope information for landslide detection $[6,46]$. 


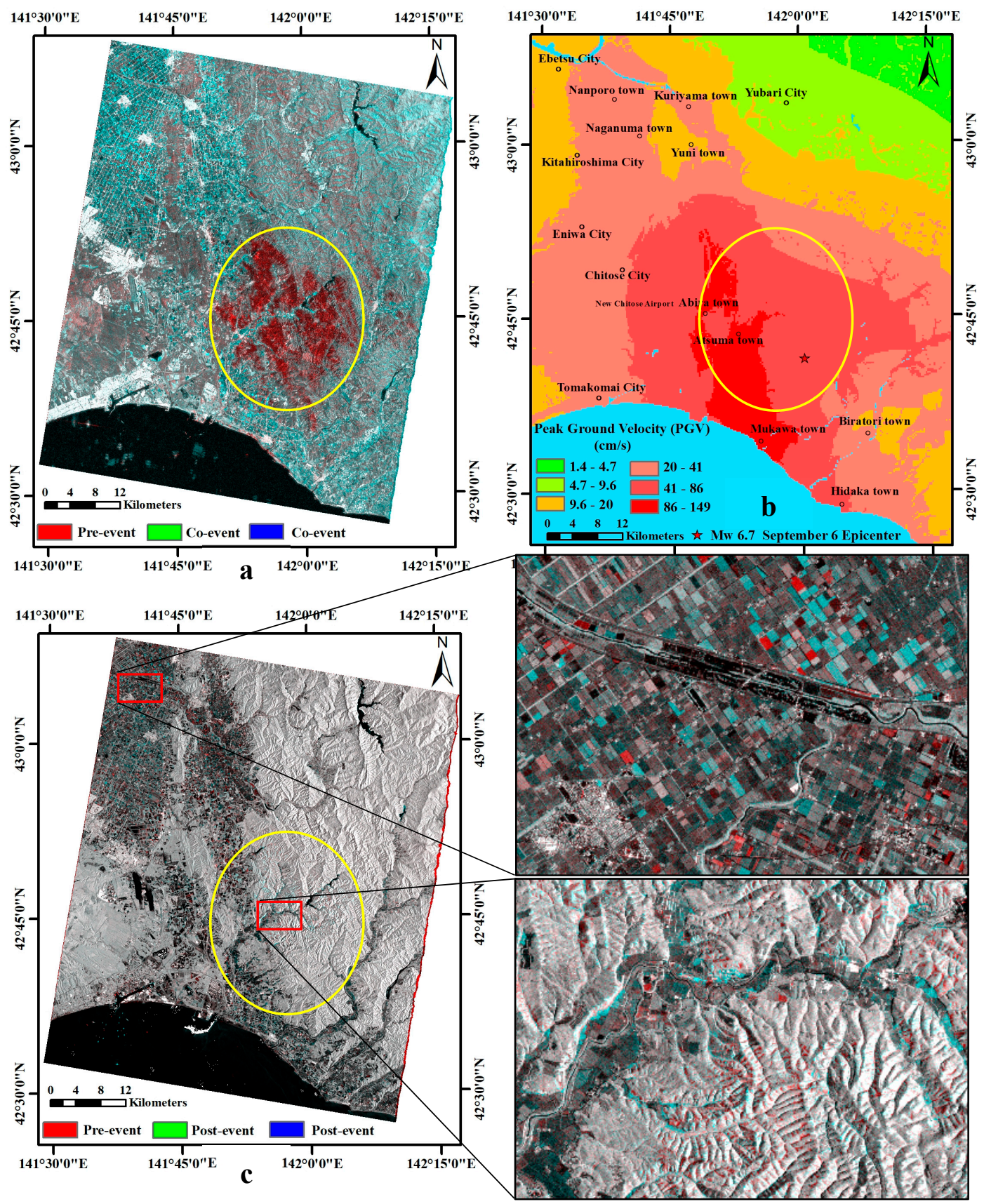

Figure 15. Color composite image of coherence from descending PALSAR-2 pairs (a); peak ground velocity around the Atsuma town on September 6, 2018 (b), downloaded from QuiQuake: https: //gbank.gsj.jp/QuiQuake/QuakeMap/index.en.html.; the color composite of backscattering intensity from descending PALSAR-2 images (c).

Moreover, the use of landslide triggering factors (e.g., earthquake or rainfalls) as additional input may also improve the classification ability of SAR-based methods. From Figure 15b, we can assume that the possibility of landslide occurrence is higher in areas with higher peak ground velocity (PGV). This assumption may help to limit the areas where landslides possibly occur. Considering the coverage of the reference optical images and the availability of descending and ascending track PALSAR-2 images, we chose the common area of the optical and SAR images as the study area. In our study area, the effects of seismic motion are almost the same. Thus, we only used the slope as an additional input for the SAR data. For large-scale landslide mapping, the seismic motion can be an additional input 
to be used along with the SAR products. Our results encourage further research that might include fine-tuning of the procedure according to the triggering factors of landslides and the geo-environmental characteristics of specific areas.

\section{Conclusions}

In this study, six ALOS-2 PALSAR-2 data from descending and ascending orbits, taken before and after the 2018 Hokkaido Eastern Iburi earthquake, were employed to identify and map earthquake-triggered landslides in mountainous areas. Six different combinations using coherence and intensity differences were implemented with a rule-based decision tree classification scheme. The decision tree classification was established based on the calculated pre- and co-event coherence difference, the pre- and post-event intensity difference, DEM, and slope. Moreover, the accuracy of the classification results was compared with high-resolution optical satellite images and the truth data by GSI, Japan. The results showed that SAR coherence and intensity have great potential for quickly identifying and mapping earthquake-induced landslides. The detected landslides show a good match with the reference optical images. The quantitative comparison results showed that the descending and ascending intensity-based landslide classification had the best accuracy, compared to the other methods. Considering the complexity of vegetated mountain terrain and the side-looking nature of SAR sensors, not all the aspects of the terrain were measured. Thus, the combined use of the ascending and descending path data was effective in this case study.

Author Contributions: Conceptualization, Y.A., W.L. and F.Y.; methodology and software, Y.A.; validation and investigation, Y.A., W.L., F.Y. and Y.M.; data curation, W.L. and F.Y.; writing-original draft preparation, Y.A.; writing-review and editing, W.L., F.Y. and Y.M.; project administration, F.Y. and Y.M.; funding acquisition, F.Y.

Funding: This research was partially funded by JST CREST Grant Number JPMJCR1411, Japan, and JSPS KAKENHI Grant Number 17H02066, Japan.

Acknowledgments: The ALOS-2 PALSAR-2 data used in this study are owned by the Japan Aerospace Exploration Agency (JAXA) and were provided for the ALOS-2 research program (RA6, PI No.3243).

Conflicts of Interest: The authors declare no conflicts of interest.

\section{References}

1. Roback, K.; Clark, M.K.; West, A.J.; Zekkos, D.; Li, G.; Gallen, S.F.; Chamlagain, D.; Godt, J.W. The size, distribution, and mobility of landslides caused by the $2015 \mathrm{M}_{\mathrm{w}} 7.8$ Gorkha earthquake, Nepal. Geomorphology 2018, 301, 121-138. [CrossRef]

2. Plank, S. Rapid damage assessment by means of multi-temporal SAR-A comprehensive review and outlook to Sentinel-1. Remote Sens. 2014, 6, 4870-4906. [CrossRef]

3. Tofani, V.; Segoni, S.; Agostini, A.; Catani, F.; Casagli, N. Technical Note: Use of remote sensing for landslide studies in Europe. Nat. Hazards Earth Syst. Sci. 2013, 13, 299-309. [CrossRef]

4. Casagli, N.; Frodella, W.; Morelli, S.; Tofani, V.; Ciampalini, A.; Intrieri, E.; Raspini, F.; Rossi, G.; Tanteri, L.; $\mathrm{Lu}, \mathrm{P}$. Spaceborne, UAV and ground-based remote sensing techniques for landslide mapping, monitoring and early warning. Geoenviron. Disasters 2017, 4, 9. [CrossRef]

5. Liu, X.; Zhao, C.; Zhang, Q.; Peng, J.; Zhu, W.; Lu, Z. Multi-temporal loess landslide inventory mapping with C-, X- and L-band SAR datasets-a case study of Heifangtai loess landslides, China. Remote Sens. 2018, 10, 2756. [CrossRef]

6. Plank, S.; Twele, A.; Martinis, S.; Plank, S.; Twele, A.; Martinis, S. Landslide mapping in vegetated areas using change detection based on optical and polarimetric SAR data. Remote Sens. 2016, 8, 307. [CrossRef]

7. $\quad$ Burrows, K.; Walters, R.J.; Milledge, D.; Spaans, K.; Densmore, A.L.; Burrows, K.; Walters, R.J.; Milledge, D.; Spaans, K.; Densmore, A.L. A new method for large-scale landslide classification from Satellite Radar. Remote Sens. 2019, 11, 237. [CrossRef]

8. Strozzi, T.; Ambrosi, C.; Raetzo, H.; Strozzi, T.; Ambrosi, C.; Raetzo, H. Interpretation of aerial photographs and satellite SAR interferometry for the inventory of landslides. Remote Sens. 2013, 5, 2554-2570. [CrossRef] 
9. Bardi, F.; Frodella, W.; Ciampalini, A.; Bianchini, S.; Del Ventisette, C.; Gigli, G.; Fanti, R.; Moretti, S.; Basile, G.; Casagli, N. Integration between ground based and satellite SAR data in landslide mapping: The San Fratello case study. Geomorphology 2014, 223, 45-60. [CrossRef]

10. Dong, J.; Zhang, L.; Li, M.; Yu, Y.; Liao, M.; Gong, J.; Luo, H. Measuring precursory movements of the recent Xinmo landslide in Mao County, China with Sentinel-1 and ALOS-2 PALSAR-2 datasets. Landslides 2018, 15, 135-144. [CrossRef]

11. Watanabe, M.; Thapa, R.B.; Ohsumi, T.; Fujiwara, H.; Yonezawa, C.; Tomii, N.; Suzuki, S. Detection of damaged urban areas using interferometric SAR coherence change with PALSAR-2. Earth Planets Space 2016, 68, 131. [CrossRef]

12. Karimzadeh, S.; Mastuoka, M. Building damage assessment using multisensor dual-polarized synthetic aperture radar data for the 2016 M 6.2 Amatrice Earthquake, Italy. Remote Sens. 2017, 9, 330. [CrossRef]

13. Moya, L.; Zakeri, H.; Yamazaki, F.; Liu, W.; Mas, E.; Koshimura, S. 3D gray level co-occurrence matrix and its application to identifying collapsed buildings. ISPRS J. Photogramm. Remote Sens. 2019, 149, 14-28. [CrossRef]

14. Ferrentino, E.; Marino, A.; Nunziata, F.; Migliaccio, M. A dual-polarimetric approach to earthquake damage assessment. Int. J. Remote Sens. 2019, 40, 197-217. [CrossRef]

15. Goorabi, A. Detection of landslide induced by large earthquake using InSAR coherence techniques Northwest Zagros, Iran. Egypt. J. Remote Sens. Space Sci. 2019. [CrossRef]

16. Mondini, A.C.; Santangelo, M.; Rocchetti, M.; Rossetto, E.; Manconi, A.; Monserrat, O. Sentinel-1 SAR amplitude imagery for rapid landslide detection. Remote Sens. 2019, 11, 760. [CrossRef]

17. Uemoto, J.; Moriyama, T.; Nadai, A.; Kojima, S.; Umehara, T. Landslide detection based on height and amplitude differences using pre- and post-event airborne X-band SAR data. Nat. Hazards 2019, 95, 485-503. [CrossRef]

18. Vöge, M.; Frauenfelder, R.; Ekseth, K.; Arora, M.K.; Bhattacharya, A.; Bhasin, R.K. The use of SAR interferometry for landslide mapping in the Indian Himalayas. In Proceedings of the 36th International Symposium on Remote Sensing of Environment, Berlin, Germany, 7-10 May 2015; Volume XL-7/W3, pp. 857-863. [CrossRef]

19. Intrieri, E.; Raspini, F.; Fumagalli, A.; Lu, P.; Del Conte, S.; Farina, P.; Allievi, J.; Ferretti, A.; Casagli, N. The Maoxian landslide as seen from space: Detecting precursors of failure with Sentinel-1 data. Landslides 2018, 15, 123-133. [CrossRef]

20. Dai, K.; Chen, G.; Xu, Q.; Li, Z.; Qu, T.; Hu, L.; Lu, H. Potential landslide early detection near Wenchuan by a qualitatively multi-baseline DInSAR method. In Proceedings of the ISPRS TC III Mid-term Symposium "Developments, Technologies and Applications in Remote Sensing", Beijing, China, 7-10 May 2018; Volume XLII-3, pp. 253-256. [CrossRef]

21. Yamagishi, H.; Yamazaki, F. Landslides by the 2018 Hokkaido Iburi-Tobu Earthquake on September 6. Landslides 2018, 15, 2521-2524. [CrossRef]

22. Normile, D. Slippery Volcanic Soils Blamed for Deadly Landslides during Hokkaido Earthquake. Available online: https:/www.sciencemag.org/news/2018/09/slippery-volcanic-soils-blamed-deadlylandslides-during-hokkaido-earthquake (accessed on 30 August 2019).

23. Geospatical Informatio Authority of Japan (GSI). 2018-Hokkaido Eastern Iburi Earthquake. Available online: http://www.gsi.go.jp/BOUSAI/H30-hokkaidoiburi-east-earthquake-index.html\#1 (accessed on 18 May 2019).

24. Fujiwara, S.; Nakano, T.; Morishita, Y.; Kobayashi, T.; Yarai, H.; Une, H.; Hayashi, K. Detection and interpretation of local surface deformation from the 2018 Hokkaido Eastern Iburi Earthquake using ALOS-2 SAR data. Earth Planets Space 2019, 71, 64. [CrossRef]

25. Shao, X.; Ma, S.; Xu, C.; Zhang, P.; Wen, B.; Tian, Y.; Zhou, Q.; Cui, Y.; Shao, X.; Ma, S.; et al. Planet image-based inventorying and machine learning-based susceptibility mapping for the landslides triggered by the $2018 \mathrm{M}_{\mathrm{w}} 6.6$ Tomakomai, Japan Earthquake. Remote Sens. 2019, 11, 978. [CrossRef]

26. Ohtani, M.; Imanishi, K. Seismic potential around the 2018 Hokkaido Eastern Iburi earthquake assessed considering the viscoelastic relaxation. Earth Planets Space 2019, 71, 57. [CrossRef]

27. Osanai, N.; Yamada, T.; Hayashi, S.; Kastura, S.; Furuichi, T.; Yanai, S.; Murakami, Y.; Miyazaki, T.; Tanioka, Y.; Takiguchi, S.; et al. Characteristics of landslides caused by the 2018 Hokkaido Eastern Iburi Earthquake. Landslides 2019, 16, 1517-1528. [CrossRef] 
28. Geospatical Informatio Authority of Japan (GSI). Fundamental Geospatial Data portal of GSI. Available online: https://fgd.gsi.go.jp/download/menu.php (accessed on 16 March 2018).

29. Bamler, R.; Hartl, P. Synthetic aperture radar interferometry. Inverse Probl. 1998, 14, R1-R54. [CrossRef]

30. Ferretti, A.; Monti-Guarnieri, A.; Prati, C.; Rocca, F. InSAR Principles: Guidelines for SAR Interferometry Processing and Interpretation; Karen, F., Ed.; ESA Publications: Noordwijk, The Netherlands, 2007; ISBN 9290922338.

31. Zebker, H.A.; Villasenor, J. Decorrelation in interferometric radar echoes. IEEE Trans. Geosci. Remote Sens. 1992, 30, 950-959. [CrossRef]

32. Konishi, T.; Suga, Y. Landslide detection using COSMO-SkyMed images: A case study of a landslide event on Kii Peninsula, Japan. Eur. J. Remote Sens. 2018, 51, 205-221. [CrossRef]

33. Aspert, F.; Bach-Cuadra, M.; Cantone, A.; Holecz, F.; Thiran, J.-P. Time-Varying Segmentation for Mapping of Land Cover Changes; ENVISAT Symposium: Montreux, Switzerland, 2007.

34. Vázquez-Jiménez, R.; Ramos-Bernal, R.N.; Romero-Calcerrada, R.; Arrogante-Funes, P.; Tizapa, S.S.; Novillo, C.J. Thresholding algorithm optimization for change detection to satellite imagery. In Color Image Process, 1st ed.; Travieso-Gonzalez, C., Ed.; IntechOpen: London, UK, 2018; pp. 163-182. [CrossRef]

35. D'Addabbo, G.S.A. Three different unsupervised methods for change detection: An application. In Proceedings of the IEEE International Geoscience and Remote Sensing Symposium, Anchorage, AK, USA, 22-24 September 2004; Volume 3, pp. 1980-1983. [CrossRef]

36. Elnaggar, A.; Noller, J.; Elnaggar, A.A.; Noller, J.S. Application of remote-sensing data and decision-tree analysis to mapping salt-affected soils over large areas. Remote Sens. 2009, 2, 151-165. [CrossRef]

37. Aimaiti, Y.; Kasimu, A.; Jing, G. Urban landscape extraction and analysis based on optical and microwave ALOS satellite data. Earth Sci. Informatics. 2016, 9, 425-435. [CrossRef]

38. Shimada, M. ALOS, ALOS-2 and Solid Earth Observations. In Proceedings of the PIXEL workshop, Kyoto, Japan, 22 December 2011; Available online: http://www.eri.u-tokyo.ac.jp/people/yaoki/seika_2011/pdf/ presen01.pdf (accessed on 30 September 2019).

39. Plank, S.; Singer, J.; Minet, C.; Thuro, K. Pre-survey suitability evaluation of the differential synthetic aperture radar interferometry method for landslide monitoring. Int. J. Remote Sens. 2012, 33, 6623-6637. [CrossRef]

40. Stramondo, S.; Bignami, C.; Chini, M.; Pierdicca, N.; Tertulliani, A. Satellite radar and optical remote sensing for earthquake damage detection: Results from different case studies. Int. J. Remote Sens. 2006, 27, 4433-4447. [CrossRef]

41. Matsuoka, M.; Yamazaki, F. Use of satellite SAR intensity imagery for detecting building areas damaged due to Earthquakes. Earthq. Spectra 2004, 20, 975-994. [CrossRef]

42. Shimada, M.; Watanabe, M.; Kawano, N.; Ohki, M.; Motooka, T.; Wada, Y. Detecting mountainous landslides by SAR polarimetry: A comparative study using Pi-SAR-L2 and X-band SARs. Trans. Japan Soc. Aeronaut. Space Sci. Aerosp. Technol. Japan 2014, 12, Pn_9-Pn_15. [CrossRef]

43. Luo, S.; Tong, L.; Chen, Y.; Tan, L. Landslides identification based on polarimetric decomposition techniques using Radarsat-2 polarimetric images. Int. J. Remote Sens. 2016, 37, 2831-2843. [CrossRef]

44. Park, S.-E.; Lee, S.-G. On the use of single-, dual-, and quad-polarimetric SAR observation for landslide detection. ISPRS Int. J. Geo-Inf. 2019, 8, 384. [CrossRef]

45. Tsuchida, R.; Liu, W.; Yamazaki, F. Detection of Landslides in the 2015 Gorkha, Nepal Earthquake using satellite imagery. In Proceedings of the 36th Asian Conference on Remote Sensing: Fostering Resilient Growth in Asia, Metro Manila, Philippines, 19-23 October 2015; Available online: http://ares.tu.chiba-u.jp/ yamazaki/pdf/proceeding/2015ACRS_Tsuchida.pdf (accessed on 30 September 2019).

46. Liu, W.; Yamazaki, F. Detection of landslides due to the 2013 Thypoon Wipha from high-resolution airborne SAR images. In Proceedings of the IEEE International Geoscience and Remote Sensing Symposium (IGARSS), Milan, Italy, 26-31 July 2015. [CrossRef]

(C) 2019 by the authors. Licensee MDPI, Basel, Switzerland. This article is an open access article distributed under the terms and conditions of the Creative Commons Attribution (CC BY) license (http://creativecommons.org/licenses/by/4.0/). 